\title{
Morphology and Properties of ZnO Films Obtained by Repeated Spin Coating on Porous Silicon Substrates
}

\author{
V. S. Zakhvalinskii ${ }^{a}, *$ I. M. Golev ${ }^{b}$, L. V. Borisenko ${ }^{a}$, T. V. Prokopova ${ }^{b}$, \\ A. N. Khmara ${ }^{a}$, E. A. Pilyuk ${ }^{a}$, and D. A. Kolesnikov ${ }^{a}$ \\ ${ }^{a}$ Belgorod State National Research University, Belgorod, 308015 Russia \\ ${ }^{b}$ Air Force Academy Scientific and Educational Center, Voronezh, 394064 Russia \\ *e-mail:zakhvalinskii@bsu.edu.ru
}

\begin{abstract}
Layers of porous silicon (PS), multilayered $\mathrm{ZnO}$ films, and heterostructures based on them are obtained. The surface morphology, chemical and phase composition of the PS layers and $\mathrm{ZnO}$ films, and the transverse cleavage of $\mathrm{ZnO}-\mathrm{PS}$ nanocomposite, are investigated via energy-dispersive $\mathrm{X}$-ray spectral analysis (EDX), X-ray diffraction (XRD), and scanning electron microscopy (SEM). The current-voltage characteristics of $\mathrm{Al} / \mathrm{Ag} / p-\mathrm{Si}(100) / \mathrm{PS} / \mathrm{ZnO} / \mathrm{Ag} / \mathrm{Al}$ and $\mathrm{Al} / \mathrm{Ag} / p-\mathrm{Si}(100) / \mathrm{PS} / \mathrm{ZnO} / \mathrm{SiC} / \mathrm{Ag} / \mathrm{Al}$ heterostructures are studied.
\end{abstract}

DOI: $10.3103 / \mathrm{S} 1062873816090495$

\section{INTRODUCTION}

Zinc oxide $(\mathrm{ZnO})$ is a wide-bandgap semiconductor with wide practical applications in catalysts, gas and chemical sensors, surface acoustic-wave devices, solar cells [1-3], and optoelectronic devices [4]. One way of improving the efficiency of white-light sources based on $\mathrm{ZnO}$ is the use of nanocomposites. A developed surface of porous silicon (PS) layers is a good substrate for nanocomposite white-light sources based on $\mathrm{ZnO}$. Is has been established that zinc oxideporous silicon ( $\mathrm{ZnO}-\mathrm{PS})$ composites exhibit an increase in white light emission in the 1.4 to $3.3 \mathrm{eV}$ range of the electromagnetic spectrum [5]. A common way of creating sources of intense white light is mixing the radiation from red, green, and blue light-emitting diodes [6]. The efficiency of such white-light sources is confirmed by the results from investigating the photoluminescence of $\mathrm{ZnO}-\mathrm{PS}$ nanocomposites upon excitation with a $\mathrm{HeCd}$ laser $(3.81 \mathrm{eV})$. In an intense spectrum, three peaks are observed in the range of 1.4 to $3.3 \mathrm{eV}$ : red $(1.69 \mathrm{eV})$, green $(2.34 \mathrm{eV})$, and blue $(2.88 \mathrm{eV})$ [5]. Heterostructures based on $\mathrm{ZnO}-\mathrm{PS}$ nanocomposites are obtained via the wet sol-gel technique by means of spin coating [7] and the high-frequency sputtering of $\mathrm{ZnO}$ onto a PS substrate [8]. A variety of approaches to obtaining nanosized $\mathrm{ZnO}$ samples that take advantage of the electronic, optical, and piezoelectric properties of zinc oxide [9] are used in, e.g., designing low-threshold ultraviolet lasers that operate at room temperature $[10,11]$.

Obtaining diode structures based on porous silicon and zinc oxide is therefore of great interest. The aim of this work was to obtain porous silicon, deposit $\mathrm{ZnO}$ layers via repeated (sol-gel) spin coating, and inves- tigate a $\mathrm{ZnO}-\mathrm{PS}$ composite and diode structures based on it.

\section{EXPERIMENTAL}

Layers of PS were obtained via the electrochemical etching of single-crystal $p$-type silicon wafers of grade KDB-2 with crystallographic orientation (100). Prior to etching, aluminum films and then silver films were formed via thermal vacuum deposition on the unpolished sides of the wafers, which were preliminarily cleansed of their $\mathrm{SiO}_{2}$ layers. The deposition of a reverse metal electrode was part of the process of obtaining porous silicon by anodizing in a solution. To create reliable ohmic contacts, the films were annealed in a vacuum oven at $450^{\circ} \mathrm{C}$ for $30 \mathrm{~min}$. The ends of the samples were protected from etching with layers of paraffin. Etching was done in an electrolyte with composition $\mathrm{HF}(48 \%): \mathrm{C}_{2} \mathrm{H}_{5} \mathrm{OH}=1: 1$ in the direct current mode with stirring of the electrolyte. The drop in voltage across the electrochemical cell was on the order of 1.2 to $1.8 \mathrm{~V}$. The samples were washed with isopropyl alcohol, acetone, and petroleum ether.

The samples were then covered with zinc oxide via spin coating. A $0.3 \mathrm{M}$ solution of monoethanolamine (MEA) was added to a $0.3 \mathrm{M}$ solution of zinc acetate $\mathrm{Zn}\left(\mathrm{CH}_{3} \mathrm{COO}\right)_{2} \cdot 12 \mathrm{H}_{2} \mathrm{O}$ in ethyl alcohol in a ratio of $1: 1$. The resulting solution was deposited seven times $(N=7)$ on the PS surfaces, with the samples being subjected to spin coating and subsequent preliminary annealing for $10 \mathrm{~min}$ at $T=275^{\circ} \mathrm{C}$ after each deposition cycle. The process of obtaining multilayered $\mathrm{ZnO}$ films was completed by annealing the samples for $10 \mathrm{~min}$ at $T=650^{\circ} \mathrm{C}$. 
(a)

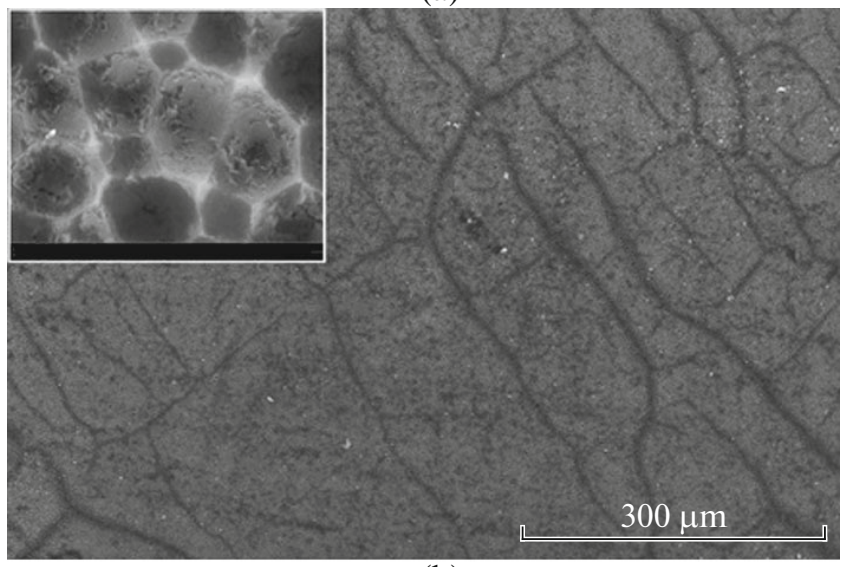

(b)

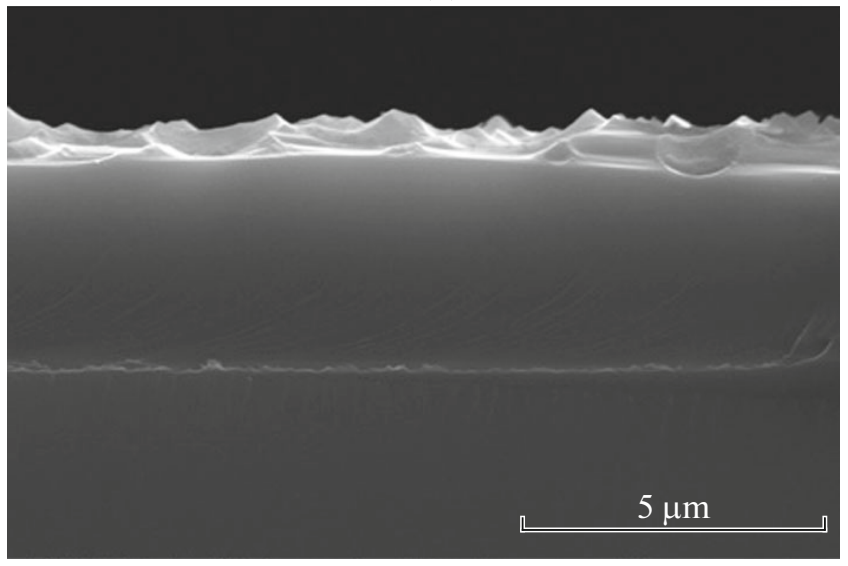

Fig. 1. (a) Surface morphology of $p$-Si (100) at the onset of PS formation; magnification in the insert is $\times 50000$. (b) Image of the cleavage of the $p$-Si (100) sample at the initial step of anodizing.

The phase composition and crystal structure of the resulting $\mathrm{ZnO}$ films were examined via $\mathrm{X}$-ray diffraction on a Rigaku IV diffractometer. Survey mode: $\theta-2 \theta$ in the $10-100^{\circ}$ range of angles; Ni filter, $K_{\beta}$; $\mathrm{Cu} K_{\alpha}$ radiation with $\lambda=1.54056 \AA$; no monochromator; and Bragg-Brentano geometry. It was established that the resulting films were composed of hexagonal zinc oxide with space group $\mathrm{P} 6_{3} \mathrm{mc}(a=3.2533 \AA$ and $c=5.2073 \AA)$. The chemical composition of the obtained films was monitored by means of energy-dispersive X-ray spectroscopy (EDX). It was found that the films' composition corresponded to $\mathrm{ZnO}$. EDX spectra, cross sections of the $\mathrm{ZnO}-\mathrm{PS}$ nanocomposite, and the surface morphology of the $\mathrm{ZnO}$ films were studied on Quanta 600 3D and Nova Nano 450 scanning electron microscopes.

The heterostructure of $\mathrm{Al} / \mathrm{Ag} / p-\mathrm{Si}(100) /$ $\mathrm{PS} / \mathrm{ZnO} / \mathrm{Ag} / \mathrm{Al}$ was obtained after the thermal vacuum deposition of $\mathrm{Al} / \mathrm{Ag}$ ohmic contacts.

Additional passivating $\mathrm{SiC}$ layers were deposited via nonreactive high-frequency magnetron sputtering, (a)

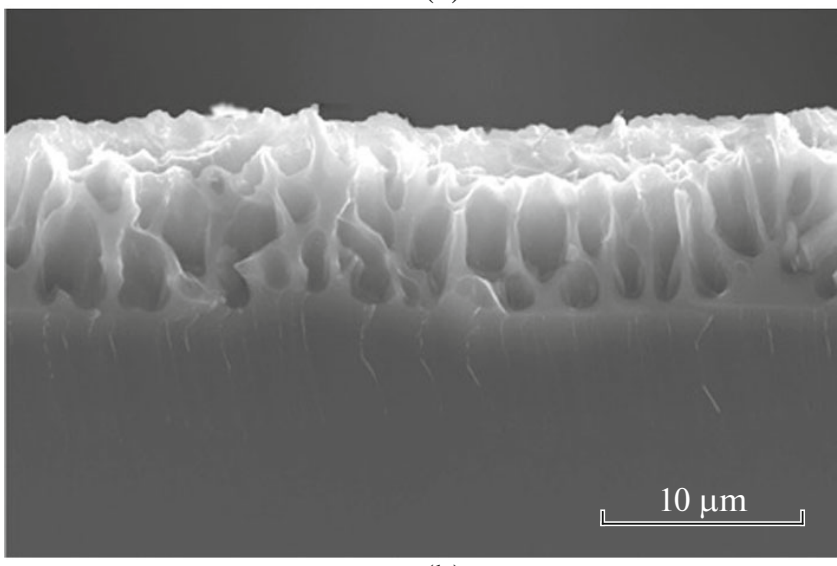

(b)

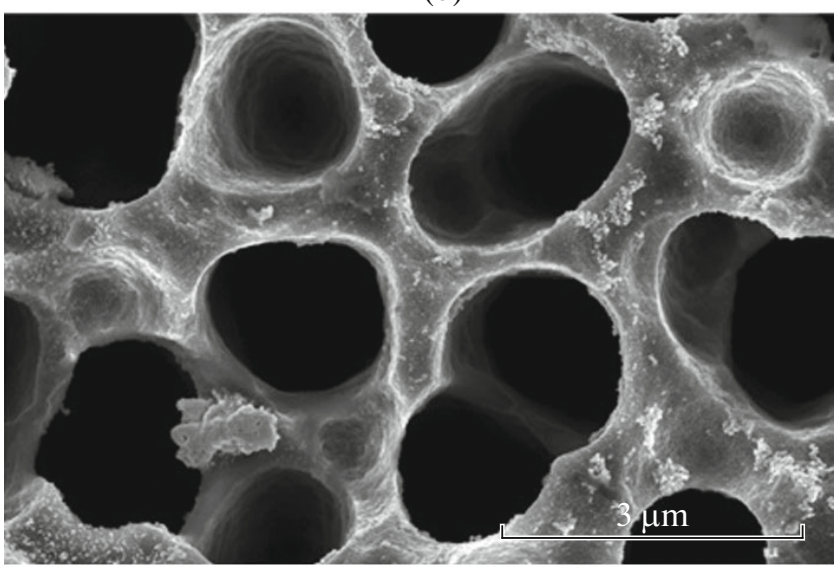

Fig. 2. Images of (a) the PS surface and (b) cleavage of the $\mathrm{PS} / p$-Si (100) sample, obtained at a current density of $j=$ $15 \mathrm{~mA} \mathrm{~cm}^{-2}$ and an etching time of $t=50 \mathrm{~min}$.

and the heterostructure of $\mathrm{Al} / \mathrm{Ag} / p-\mathrm{Si}(100) / \mathrm{PS} /$ $\mathrm{ZnO} / \mathrm{SiC} / \mathrm{Ag} / \mathrm{Al}$ was obtained.

Both heterostructures were also investigated from the viewpoint of their current-voltage characteristics.

\section{RESULTS AND DISCUSSION}

We investigated the process of pore formation in $p$-Si (100) upon anodization in an electrolyte based on ethyl alcohol. The samples turned out to be covered with pits with spherical surfaces, i.e., etching islands, the initial phase of pore formation. The current density was $j=25 \mathrm{~mA} \mathrm{~cm}{ }^{-2}$; the etching time was $t=$ $15 \mathrm{~min}$. The results from investigating the surface morphologies and cleavage of the samples on a scanning electron microscope are shown in Fig. 1. Subsequent etching of the samples' surfaces resulted in the emergence of lighter square contours, i.e., subcells. The subcells were formed by crystal planes (001) perpendicular to the surfaces. The subcells of a macroporous silicon layer are seen in Fig. 2a; the cleavage of a $\mathrm{PS} / p$-Si (100) sample obtained at a current density of 
(a)

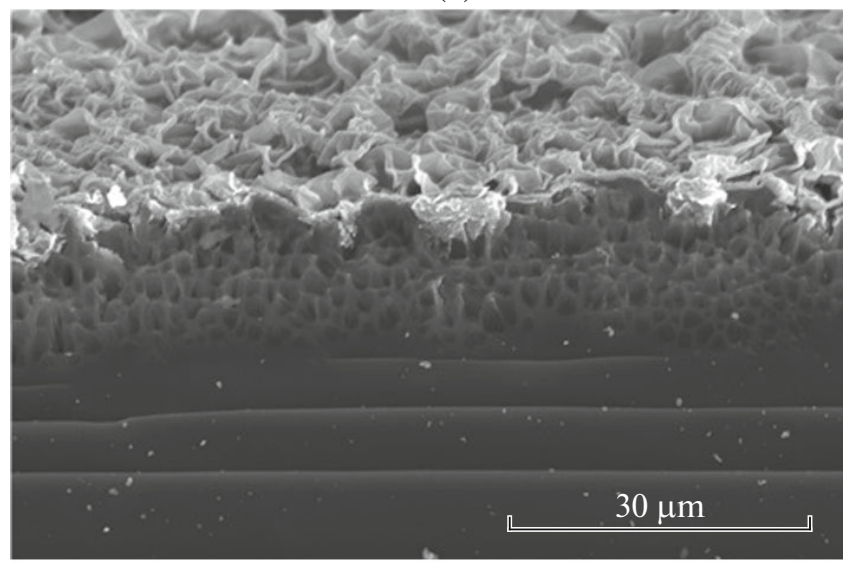

(b)

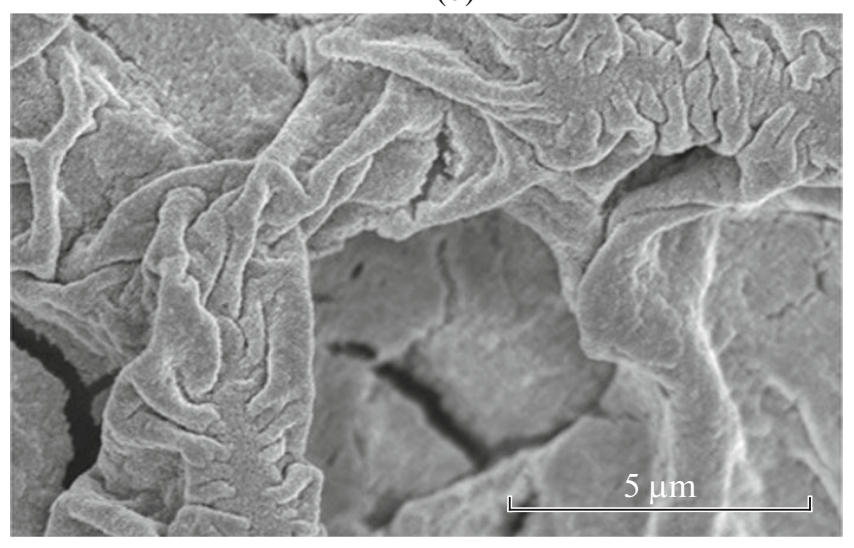

Fig. 3. Surface of the $\mathrm{ZnO}$ film: (a) cross section of the $\mathrm{ZnO} / \mathrm{PS}$ heterostructure, viewed on a Quanta 600 3D scanning electron microscope; (b) surface of the outer $\mathrm{ZnO}$ film layer.

$j=15 \mathrm{~mA} \mathrm{~cm}{ }^{-2}$ and an etching time of $t=50 \mathrm{~min}$ is shown in Fig. 2b. These conditions of anodization ensured the formation of a macroporous silicon layer $9.7 \mu \mathrm{m}$ thick with an average pore diameter of $1.92 \mu \mathrm{m}$ on the sample's surface.

After obtaining porous silicon layers, a layer of solution containing zinc acetate and monoethanolamine in ethyl alcohol, preliminarily held until a solgel had formed, was applied to the samples. $\mathrm{ZnO}$ films were obtained by spin coating in combination with drying and annealing.

The surface morphologies of the $\mathrm{ZnO}$ films deposited on the porous silicon layers were examined on Quanta 600 3D and Nova Nano 450 scanning electron microscopes. Figure 3a shows a cross section of the $\mathrm{ZnO} / \mathrm{PS}$ heterostructure, obtained on a Quanta 600 $3 \mathrm{D}$ scanning electron microscope. The cellular structure of porous silicon is clearly seen on the cleavage. Figure $3 \mathrm{~b}$ shows the results from investigating the surface morphology of the multilayered $\mathrm{ZnO}$ coating. As can be seen from Fig. 3b, the surfaces of the $\mathrm{ZnO}$ films

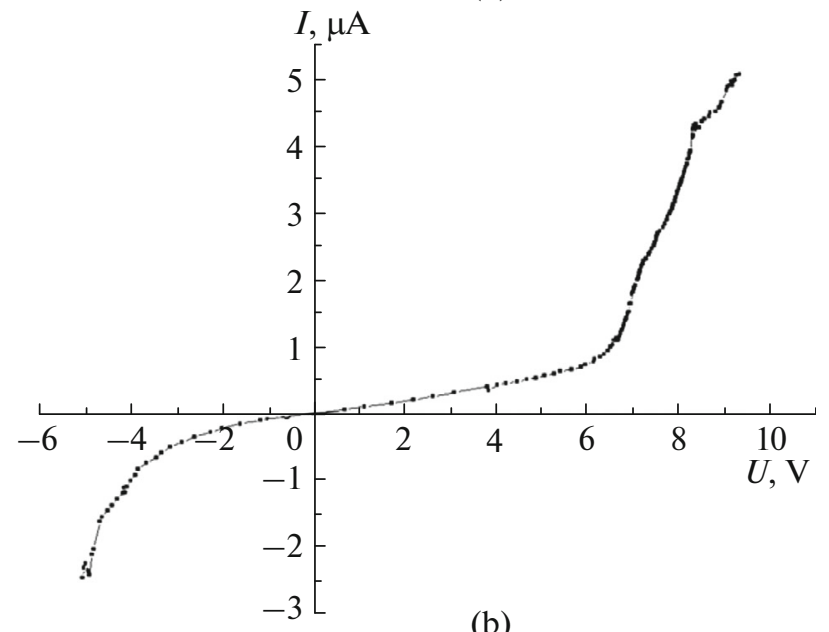

(b)

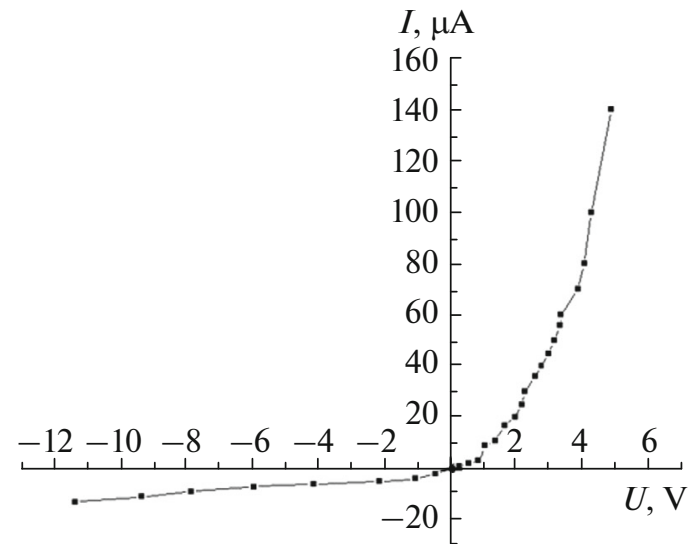

Fig. 4. Current-voltage characteristics of heterostructures (a) $\mathrm{Al} / \mathrm{Ag} / p-\mathrm{Si}(100) / \mathrm{PS} / \mathrm{ZnO} / \mathrm{Ag} / \mathrm{Al}$ and (b) $\mathrm{Al} / \mathrm{Ag} /$ $p-\mathrm{Si}(100) / \mathrm{PS} / \mathrm{ZnO} / \mathrm{SiC} / \mathrm{Ag} / \mathrm{Al}$.

are developed and covered with cracks. The employed technology of sol-gel application by spin coating with subsequent annealing allows us to obtain continuous coatings only for multilayered $\mathrm{ZnO}$ films.

The current-voltage characteristics of the $\mathrm{Al} / \mathrm{Ag} / p-\mathrm{Si}(100) / \mathrm{PS} / \mathrm{ZnO} / \mathrm{Ag} / \mathrm{Al}$ and $\mathrm{Al} / \mathrm{Ag} /$ $p-\mathrm{Si}(100) / \mathrm{PS} / \mathrm{ZnO} / \mathrm{SiC} / \mathrm{Ag} / \mathrm{Al}$ heterostructures of were studied at room temperature. As can be seen from Fig. 4a, the employed spin coating technology with subsequent annealing allowed the creation of a diode heterostructure based on porous silicon and $\mathrm{ZnO}$. The characteristics of such a diode structure were considerably enhanced after the deposition of a passivating $\mathrm{SiC}$ layer. Figure $4 \mathrm{~b}$ shows that the maximum forward current in the $\mathrm{Al} / \mathrm{Ag} / p-\mathrm{Si}(100) / \mathrm{PS} / \mathrm{ZnO} / \mathrm{SiC} / \mathrm{Ag} / \mathrm{Al}$ heterostructure rose by almost two orders of magnitude, while the maximum reverse voltage rose more than $400 \%$, compared to the $\mathrm{Al} / \mathrm{Ag} / p-\mathrm{Si}(100) /$ $\mathrm{PS} / \mathrm{ZnO} / \mathrm{Ag} / \mathrm{Al}$ heterostructure. 


\section{CONCLUSIONS}

Layers of porous silicon were obtained on singlecrystal $p-\mathrm{Si}(100)$ substrates by anodizing in a solution. Multilayered $\mathrm{ZnO}$ films were obtained by repeated spin coating, decomposition, drying, and annealing of sol-gel layers (sol-gel spin coating). The technology of film preparation is based on the repeated application of layers of zinc acetate $\mathrm{Zn}\left(\mathrm{CH}_{3} \mathrm{COO}\right)_{2} \cdot 12 \mathrm{H}_{2} \mathrm{O}$ solutions in isopropyl alcohol and monoethanolamine and their thermal decomposition. The surface morphologies and chemical and phase compositions of the $\mathrm{ZnO}$ films were investigated via energydispersive $\mathrm{X}$-ray spectral analysis, $\mathrm{X}$-ray diffraction, and scanning electron microscopy. Passivating $\mathrm{SiC}$ layers were deposited on the $\mathrm{ZnO}$ surfaces by means of high-frequency magnetron sputtering. The current-voltage characteristic of the resulting $\mathrm{Al} / \mathrm{Ag} / p-\mathrm{Si}(100) / \mathrm{PS} / \mathrm{ZnO} / \mathrm{Ag} / \mathrm{Al}$ heterostructure was investigated. It was shown that applying a passivating $\mathrm{SiC}$ layer on a multilayered $\mathrm{ZnO}$ film enhances the properties of the diode heterostructure. The final $\mathrm{Al} / \mathrm{Ag} / p-\mathrm{Si}(100) / \mathrm{PS} / \mathrm{ZnO} / \mathrm{SiC} / \mathrm{Ag} / \mathrm{Al}$ heterostructure exhibited a high maximum forward current and the maximum reverse voltage.

\section{ACKNOWLEDGMENTS}

This work was supported by the Russian Foundation for Basic Research, project no. 15-42-03192. Our investigations were performed on equipment at the Shared Resource Center for the Diagnostics of Structure and Properties of Nanomaterials, Belgorod State
National Research University, with the financial support of the RF Ministry of Education and Science as part of project no. 14.594.21.0010, unique code RFMEFI59414X0010.

\section{REFERENCES}

1. Nomura, K., Ohta, H., Ueda, K., et al., Science, 2003, vol. 300, p. 1269.

2. Huang, M.H., Mao, S., Feick, H., et al., Science, 2001, vol. 292, p. 1897.

3. Lee, C.T., Su, Y.K., and Wang, H.M., Thin Solid Films, 1987, vol. 150, p. 283.

4. Yamamoto, T. and Katayama-Yoshida, H., Jpn. J. Appl. Phys., 1999, vol. 38, p. L166.

5. Singh, R.G., Singh, F., Kanjilal, D., et al., J. Phys. D: Appl. Phys., 2009, vol. 42, p. 062002.

6. Schubert, E.F., Light Emitting Diodes, Cambridge: Cambridge Univ. Press, 2006, p. 431.

7. Kim, Y.-S., Taib, W.-P., and Shu, S.-J., Thin Solid Films, 2005, vol. 491, p. 153.

8. Kayahan, E., J. Lumin., 2010, vol. 130, p. 1295.

9. Nikoobakht, B., Chem. Mater., 2007, vol. 19, no. 22, p. 5279.

10. Li, L.E., Dem'yanets, L.N., Nikitin, S.I., and Lavrikov, A.S., Quantum Electron., 2006, vol. 36, p. 233.

11. Dem'yanets, L.N., Li, L.E., Uvarova, T.G., and Mininzon, Yu.M., Inorg. Mater., 2008, vol. 44, p. 40.

Translated by Z. Smirnova 